\title{
A brief history of muscular dystrophy research: A personal perspective
}

\author{
Byron A. Kakulas \\ Australian Neuromuscular Research institute, Centre for Neuromuscular and Neurological Disorders, University of Western Australia, Australia
}

\begin{abstract}
The field of myology has undergone remarkable changes. From the period of early clinical descriptions and clinical classifications, new knowledge of these disorders has come from the developments of histopathology, enzyme histochemistry and later, immunocytochemistry and electron microscopy. These techniques have enhanced the understanding of the pathophysiology of myopathies at the cellular level. The parallel evolution of molecular genetics has taken the science further not only by way of understanding and accuracy of diagnosis, but has opened up exciting possibilities of modulation of these chronic debilitating diseases. This review gives a personal perspective of the developments in the field of myology.
\end{abstract}

Key words: Genetics, genotype, histopathology, history, myology, phenotype

\section{Introduction}

In this special issue of Neurology India under the editorship of Professor Satish Khadilkar one will find articles written by a number of world experts. These contributions are intended to bring the reader up-to-date on recent progress in the field of neuromuscular diseases. As such the papers are timely and informative.

Now, in the golden era of molecular genetics, in which so many wonderful discoveries are being made it is timely to reflect on the events which preceded these developments. In the past two decades we have witnessed momentous discoveries which in themselves will endure as factual contributions to the accumulated knowledge of the age.

Unfortunately this has not always been so. Over the past 60-70 years there have been a large number of talented and devoted medical and basic scientists whose work alas has been ephemeral. This occurred because it was imperative for compassionate reasons to do something about the many incurable neuromuscular diseases confronting the clinicians, especially the muscular dystrophies. Despite their general lack of success some tribute is due to these persons whose work is now barren. It would be unreasonable to assume that this was wasted effort since all past endeavors have contributed in some way to the present happy stage. Negative results do have value in that some particular avenue has been excluded from the realm of possibilities.

On another tack it should also be recognized that the foundations for the current golden era were laid by the more basic biologists driven simply by a thirst for knowledge; and that medical scientists have simply applied these advances to their clinical problems.

In contemplating this subject it was inevitable that the names of those who had dedicated themselves to the task in the years past would come to mind. Thus I thought it would be of interest to mention just a few of those involved as a token of our appreciation.

It is appropriate that stock is taken of the milestones which have led to the splendor of the Golden Era of molecular genetics and to recall the names of those who were mainly responsible. There have been many spectacular advances in the past several decades in the field of inherited neuromuscular disorders. This review provides the reader with a sense of perspective for what has gone before and in doing so, provides a context for the contemporary reports in this special issue of Neurology India.

\section{The Beginnings}

Many of the neuromuscular disorders were identified as clinical entities in the latter $19^{\text {th }}$ century mainly by European and American physicians. Pseudohypertrophic muscular dystrophy as such was 
recognized somewhat earlier. The disorder widely known as Duchenne muscular dystrophy [DMD] was in fact first reported by Gaetano Conte in 1836 and just a few years later by Meryon in 1851. It was only in 1868 that Duchenne described the condition now commemorating his name.

During the $19^{\text {th }}$ and early $20^{\text {th }}$ centuries some effort was made to differentiate the primary from the secondary myopathies. At about this time it was realized that the seat of the disorder may be primarily in the muscle itself or that atrophy may be secondary and neurogenic in origin. However, confusion between the two possibilities persisted well into the $20^{\text {th }}$ century. The waters were further muddied by the neurogenic theory as the cause of DMD in the 1970s and 80s. It was only with the advent of DNA analysis in the past few decades that finally a clear distinction could be made possible in any given individual. An outstanding example of such confusion lay between the Kugelberg-Welander form of spinal muscular atrophy with calf enlargement and the Becker allele of DMD.

Although some effort was given to investigating the lesions microscopically, in this early period knowledge remained relatively static apart from the recognition of new clinical entities. During the late $19^{\text {th }}$ and early $20^{\text {th }}$ centuries there were many fruitless attempts to explain the origins and pathogenesis of the dystrophies but none prevailed.

\section{The Era of Myopathology}

The period of stagnation ended in 1962 when Adams, Denny-Brown and Pearson published their investigations into skeletal muscle reaction to injury in their seminal monograph 'Diseases of Muscle'. ${ }^{[1]}$ Not only did this work bring together current clinical knowledge but very importantly provided insights into the nature of muscular disorders by describing the underlying pathological processes involved. Thus, the basis for the clinical manifestations was elucidated in coherent clinico-pathological terms.

In addition to unifying the fragmented clinical landscape the work firmly placed muscle diseases well into the province of neurology. Another important contemporary work oriented to general biology rather than clinical application was Geoffrey Bourne's 'Structure and Function of Muscle'. ${ }^{[2]}$ This monograph brought together most of the biological information on muscle available at that time drawing greatly from the fields of zoology and veterinary science.

\section{Complete muscle regeneration}

Thus considerable progress had been achieved in myopathology in the latter half of the $20^{\text {th }}$ century. One of the most important of these was the discovery in 1962 of the inherent power of mammalian skeletal muscle to regenerate completely once the cause of its breakdown is removed. Previously it was believed that muscle regeneration was very limited or nonexistent. The pitfall was due to these conclusions being drawn from experiments based on surgical injuries with tearing of the sarcolemma and endomysium. In toxic metabolic or inherited muscle diseases the framework remains intact and the muscle regenerates. Pursuing this model, further experimentation with the Rottnest Island Quokka [Setonix brachyurus] established that the cause of progression of weakness in human muscular dystrophy was the result of cyclical necrosis/regeneration, leading eventually to exhaustion of regenerative capacity, outfall of muscle fibers and the end stage muscle lesion consisting of residual condensed fibrous tissue and fat.

This principle of pathogenesis is similar in all progressive primary muscle diseases where there is necrosis, irrespective of whether they are genetically determined or damaged as a result of toxic metabolic or autoimmune factors. Thus, the principles which govern the reaction of muscle to injury were laid out. ${ }^{[9]}$ The discovery that muscle possessed the power to completely regenerate gave real hope. The muscular dystrophies were potentially curable. This possibility engendered great enthusiasm worldwide, resulting in accelerated research activity enhanced by international meetings. The first major one was the $2^{\text {nd }}$ International Congress of Muscle Diseases held in Perth in 1971. However, apart from demonstrating that a membrane defect preceded necrosis in the Vitamin E deficient Quokka myopathy, in common with DMD, the molecular cause of DMD remained elusive.

\section{The Era of the Clinician}

The clinical scene also improved during the post World War II period, beginning with the publication by Walton and Nattrass in 1954 of a classification for muscular dystrophies, which remained popular until the molecular era. ${ }^{[3]}$ This classification was based on clinical and genetic factors e.g. sex-linked DMD, limb girdle muscular dystrophy (LGMD), facioscapulohumoral and myotonic forms. In 1971 John Walton edited a multiauthor book which brought together current knowledge of the 'Disorders of Voluntary Muscle,' running into many editions. ${ }^{[4]}$ As a result the clinical appreciation of distinct entities grew in number and precision. Alongside these were investigations of the inheritance patterns. In this way the genetics of the neuromuscular diseases became much better known largely due to the work of Alan Emery and Peter Becker.

The era of the clinician was exemplified by the meticulous precision of the clinical workup of patients. This was aided by the very significant laboratory assistance provided by serum creatine 
kinase estimations, an invaluable test pioneered by Hideo Sugita and Setsuro Ebashi. Combined with muscle biopsy and electrophysiology, more disease entities were clearly identified and diagnostic accuracy improved.

It must be emphasized that the great advances in molecular genetics, the finding of gene loci, their protein products and genetic mutations depends on correct clinical diagnosis, accompanied by full documentation of the pedigree with examination of affected individuals. If the clinical diagnosis was sloppy and in error, the genetic analyses would have resulted in nonsense and the modern golden era would not have eventuated.

\section{Histochemistry and electron microscopy}

Commencing with basic chemical reactions on frozen sections of muscle the techniques of histochemistry rapidly evolved to include a barrage of specific enzyme staining methods. Application of these stains to the childhood myopathies quickly resulted in an avalanche of discoveries with many new clinical entities so delineated. Examples are nemaline myopathy, central core disease and muscle fiber disproportion as well as mitochondrial disorders. Many distinguished investigators were associated with these advances; names such as Milton Shy, King Engel, Victor Dubowitz, George Karpati, Harvey Sarnat and Hans Goebel quickly come to mind.

In parallel mitochondrial cytopathies were being rapidly elucidated biochemically and histochemically. These investigations began with John Morgan-Hughes followed by others such as Anita Harding, Edward Byrne and most eminently by Salvatore [Bili] Di Mauro.

Nick Gonatas had earlier demonstrated mitochondrial changes electron microscopically. Another giant in electron microscopy was Darab Dastur who devoted a lifetime to ultrastructural studies in myopathology and neuropathology. In polymyositis, animal models had shed greater insights into the immune pathogenesis so that new classifications and better treatments evolved. Among those linked to these developments are Roger Dawkins, Marinos Dalakas and Frank Mastaglia.

Inclusion body myositis [IBM] was distinguished from polymyositis in a biopsy I had examined in 1965 for Fred Samaha as I was packing to leave Boston. Fred went on to clearly define the entity which was later elucidated electron microscopically by Sam Chou. In recent times following a career in wider fields, Valerie Askanas devoted herself to IBM, considerably advancing knowledge, an interest also taken up by Frank Mastaglia. Meanwhile hereditary IBM was identified as a separate entity by Zohar Argov a disorder now known to be identical to the Ikuya Nonaka myopathy. In this period, many of the metabolic and toxic myopathies became better known; examples being the glycogenoses and muscle disorders induced by alcohol.

\section{Myasthenia Gravis, channelopathies and the spinal muscular atrophies}

Following John Simpson's pioneer theory that myasthenia gravis [MG] was an autoimmune disease its pathogenesis became firmly established as such by the study of animal models first introduced by Patrick and Lindstrom. The aberrant neurophysiology of MG was elucidated by eminent physicians such as Ed Lambert, John Desmedt, Peter Dyck and Fritz Buchthal. Clinically, John Newsom-Davies is recognized for his astute observations and laboratory work in identifying several related autoimmune disorders of the neuromuscular junction.

The different hereditary and congenital forms of MG were delineated clinically, physiologically and morphologically by Andrew Engel and Lefkos Middleton in a very elegant style. Research in the periodic paralyses revealed the channelopathies, a field pioneered by Reinhardt Rudel and Alan Bretag.

Although spinal muscular atrophies are not in the immediate realm of this brief historical review of muscular dystrophy the contributions of Irena Hausmannowa must be acknowledged for her work in this field and in other wide-ranging areas as also of Lewis B [Bud] Rowland, especially for his motor neuron disease [ALS] studies; not to say that their original work has been confined to these disorders alone.

\section{Out of the Dark: DNA Technology and the Golden Era of Molecular Genetics}

After years of unproductive dalliance with myoblast transfer therapy came the age of DNA technology. Although some great advances had been made in the decades following World War II the most outstanding were still to come and this concerned the application of molecular genetic technology to the field.

With family pedigrees already documented by clinicians, it became readily possible to locate the gene for many of the inherited neuromuscular disorders virtually overnight. Today, this can be done for any given condition, provided there are sufficient numbers of affected individuals in the family. Usually around seven affected individuals whose DNA is available for analysis, are necessary. Isolation of the gene product rapidly follows DNA sequencing and the responsible mutation is identified. In the same way synthesis of the gene product enables Western blotting to be undertaken; affording another powerful diagnostic and research tool. In very few other instances in the history of medicine has research and diagnosis come so close together as in the era of DNA technology, changing from blind 
conjecture to true science.

In this drama there was nothing more exciting than the discovery of dystrophin and its mutations responsible for the development of DMD. Thus in trailblazing research, Lou Kunkel and his group discovered dystrophin in 1985, a membrane cytoskeletal protein related to spectrin. And at last the cause of DMD was discovered in the form of absence of dystrophin. DNA technology, reaching the stage of development in the 1980s for application to medical research heralded a revolution, particularly in the muscle field. Genetic treatments were rapidly conceived so that gene therapy was no longer just a theoretical but a practical possibility. Among the pioneers of gene therapy are John McC Howell, Shin'ichi Takeda and Terry Partridge.

Hundreds of individual neuromuscular disorders are now recognized in exact molecular terms so that a myriad of neuromuscular entities are now listed in very useful tables provided by the periodical Neuromuscular Disorders. ${ }^{[5]}$

Not to be overlooked is the importance of basic research which has enabled such advances to occur by laying the foundations. With the recognition of dystrophin and its associated membrane complex, its numerous glycoprotein elements have been isolated and most of these are now linked to a form of muscular dystrophy. Hence there are the dystrophinopathies, [DMD BMD and manifesting carriers] the sarcoglycanopathies and telethoninopathy as examples.

The nature of many neuromuscular conditions has been discovered in molecular terms and meaningful classifications have been developed. Thus neuromuscular medicine has become a science. It is extremely helpful in the clinic to have the exact molecular diagnosis available for treatment purposes, prognostications, counseling and antenatal diagnosis. Genetic selection is also all available. For instance, in dystrophia myotonica, the larger the number of DNA repeats, the more severe the disease and in BMD, the greater the amount of preserved dystrophin, the milder the condition and greater the life expectancy.

In recognizing the fact that neuromuscular research is now a predictable science rather than a compassionate but rather blind activity, it must be emphasized that none of these gratifying advances would have occurred without knowledge of pathology and reliable clinical neurology. ${ }^{[6-8]}$ Correct clinical identification is the first step in any genetic analysis. All of these wonderful advances rest on the contribution of the clinical neurologists who provide an accurate diagnosis for the technologist to follow. A diagnostic error would completely befuddle genetic analysis, giving nonsense results. None of these modern 'breakthroughs' would have been possible without the dedicated work of the clinician.

\section{Gene therapy}

The discovery of dystrophin gave great hope of a cure being rapidly developed for DMD by means of gene therapy. Great optimism was expressed in this regard at a workshop held at the Australian Neuromuscular Research Institute [ANRI] in 1992. However, despite vigorous and imaginative efforts, methods used for the introduction of a normal gene into the dystrophic muscle cell, starting with viral vectors, have been largely disappointing On the other hand the valuable clinical benefits of DNA analysis as mentioned above were quite unexpected and gratefully received.

\section{Genetic manipulation in gene therapy}

The most promising genetic therapeutic approach so far has been the alternate splicing exon skipping technique pioneered by Steve Wilton and Sue Fletcher of the ANRI. Recently, the exon skipping methodology has been refined and improved using morpholinos, replacing the antisense oligonucleotides [AOs] in bridging the mutation. In this way the post-translational RNA exclusion of the affected exon occurs, resulting in a functional gene product.

The excitement surrounding this discovery has been followed by human trials in Europe. The MRC in the UK currently supports a pioneering trial using this methodology in boys with DMD with the results to be known later in 2008. The information on premature stop codons and the resultant truncated dystrophin has led to approaches to alter these programs. Use of Gentamycin is one such example. More such approaches are likely in future. Stem cell therapy has received a lot of attention in the recent times and its impact on various neuromuscular disorders is expected to increase in the coming years. Hopefully, these developments would occur soon, to benefit the long suffering patients.

\section{A note of caution}

Although these molecular advances have led to spectacular progress in recent years, it is imperative that in searching for a cure for a human disease, a sound knowledge of the underlying pathology is a prerequisite. The disease process must be understood before experimental treatments may be designed. It is important to keep in mind that the modern era of medical practice emerged from the dark ages due to the serious postmortem study of disease mainly by German pathologists, heralded by Virchow in the $19^{\text {th }}$ century. Neglect of pathology despite all of the sophisticated diagnostic tools in this computer age would eventually be disastrous.

\section{A human viewpoint}

All this reflection brings forward some poignant and sentimental thoughts. 
In the early years research in muscular dystrophy was stimulated purely by the need to do something to help the children and their families even though the necessary knowledge was lacking. As a result there were many blind alleys and red herrings bedeviling the scene. Even so many bold and empathetic hearts applied themselves to the task, unfortunately mostly ending in frustration. In some cases, the outcome was even worse because of the false hopes generated by illconceived treatments.

So, in concluding this review, it is evident that the main thrust is to show how the muscle research enterprise has changed from being merely well intentioned but nevertheless hopeless in outcome, to one of scientific precision, leading to factual results. Thus, we have progressed from darkness to light in a way which can only be described as a dream fulfilled now, as we stand on the brink of a curative treatment in a field of research once considered hopeless and the province of fools. It was the humble Rottnest Island quokka which showed that a cure for DMD was possible and as we now reach towards closing the circle it is immensely gratifying to witness these events.

As one of the pioneers who have strived over the past 40 years and more to find a cure, I am very privileged to be among the few who have survived long enough to experience the genetic revolution and as with others, happy to have played some role in laying the groundwork for its success. This being so not only in experimental myopathology but also by providing well documented clinical cases with their family histories in readiness for DNA analysis and encouraging young scientists to join the pursuit providing intellectual and logistical support.

Among the pioneers who did not survive this long journey in time, to witness the unraveling of the enigma of muscular dystrophy, are some great and devoted men such as Massimo Aloisi, Geoffrey Bourne, Derek DennyBrown, Anil Desai, Setsuro Ebashi and Ade Milhorat.

\section{The privileged survivors}

Others who pioneered muscle research have survived long enough to witness these spectacular advances and include Raymond D Adams, Corrado Angelini, Valerie Askanas, Victor Dubowitz, Andrew Engel, King Engel, Michel Fardeau, Irena Hausmannowa, Andrew Huxley,
George Karpati, Giovanni Nigro, Frank Mastaglia, Allen Roses, Bud Rowland, Hideo Sugita, George Serratrice, Fernando Tome, John Walton and others, too numerous to name here.

\section{Proviso}

It must be stated that the selection of those mentioned is not intended to be exclusive but set out merely for the benefit of the younger reader as a representation of those involved in the early period, who have dedicated themselves to muscular dystrophy research over their lifetimes. Nor has an attempt been made to link each one with a particular contribution. Obviously there are hundreds of individuals who have made very significant contributions to the field of neuromuscular research over the years and information of this type may be gained from standard texts. My intention is simply to provide the reader with a feeling for the changes that have transpired over the decades by highlighting the way in which research has evolved, emerging from darkness to light. So on this rather sentimental note I commend the reader to the contents of this issue of Neurology India which describe the present 'state of the art' in selected fields.

\section{References}

1. Adams RD, Denny-Brown D, Pearson CM. Diseases of muscle. $1^{\text {st }}$ ed. New York: Harper and Brothers; 1952.

2. Bourne GH. The structure and function of muscle. $1^{\text {st }}$ ed. New York: Academic Press; 1972.

3. Walton JN, Nattrass FJ. On the classification natural history and treatment of the myopathies. Brain 1954;77:169-231.

4. Walton JN. Disorders of voluntary muscle. $3^{\text {rd }}$ ed. Edinborough and London: Churchill Livingstone; 1971.

5. Kaplan JC. The 2008 version of the gene table of neuromuscular disorders. Neuromusc Dis 2008;18:99-129.

6. Kakulas BA, Laing NG, Johnsen RD. The contribution of molecular genetics in the diagnosis and management of neuromuscular disorders. Scand J Rehab Med Suppl 1999;39:5-22.

7. Kakulas BA. Milestones in myopathology. Acta Myologica 2000;19: 193-200.

8. Kakulas BA. Neuromuscular diseases. Curr Opin Neurol 1996;9:367-8

9. Kakulas BA and Adams RD Diseases of Muscle Harper and Rowe Philadelphia 1985.

Accepted on 17-08-2008

Source of Support: Nil, Conflict of Interest: None declared. 
Copyright of Neurology India is the property of Medknow Publications Pvt. Ltd. and its content may not be copied or emailed to multiple sites or posted to a listserv without the copyright holder's express written permission. However, users may print, download, or email articles for individual use. 